\title{
THE BLACK-TAILED PRAIRIE DOG IN SASKATCHEWAN
}

RICHARD LAING, 504-4500 39 Street N.W., Calgary, Alberta. T3A 0M5

The Black-tailed Prairie Dog is one of five species of prairie dogs that historically ranged throughout much of the Great Plains Physiographic Zone. Black-tails are the only species of prairie dog currently found in Canada and are restricted to an area in southern Saskatchewan near the town of Val Marie. Prairie dogs have occupied native grasslands in Saskatchewan since at least the early 1900s but have been unable to colonize other areas. Because of their restricted distribution, prairie dogs have been classified as a "rare" species by the Committee On the Status of Endangered Wildlife in Canada (COSEWIC). Parks Canada has also recognized their uniqueness and included the majority of the Saskatchewan colonies within the area proposed as Grasslands National Park.

\section{Colony Distribution and Size}

Despite their classification as rare, as well as being an interesting and relatively easy species to study, prairie dogs have never been intensely studied in Canada. Accurate information on the distribution of prairie dogs in Saskatchewan is available from only three studies. Colonies were mapped in 1970, 1975 and 1985. The 1970 study was conducted specifically to determine the distribution and abundance of prairie dog colonies. In 1975 and 1985 colonies were mapped as part of feasibility studies conducted to determine the suitability of Grasslands National Park as a re-introduction site for Black-footed Ferrets.

In 1970, 15 colonies totalling 503 ha were located. By 1975, the number of

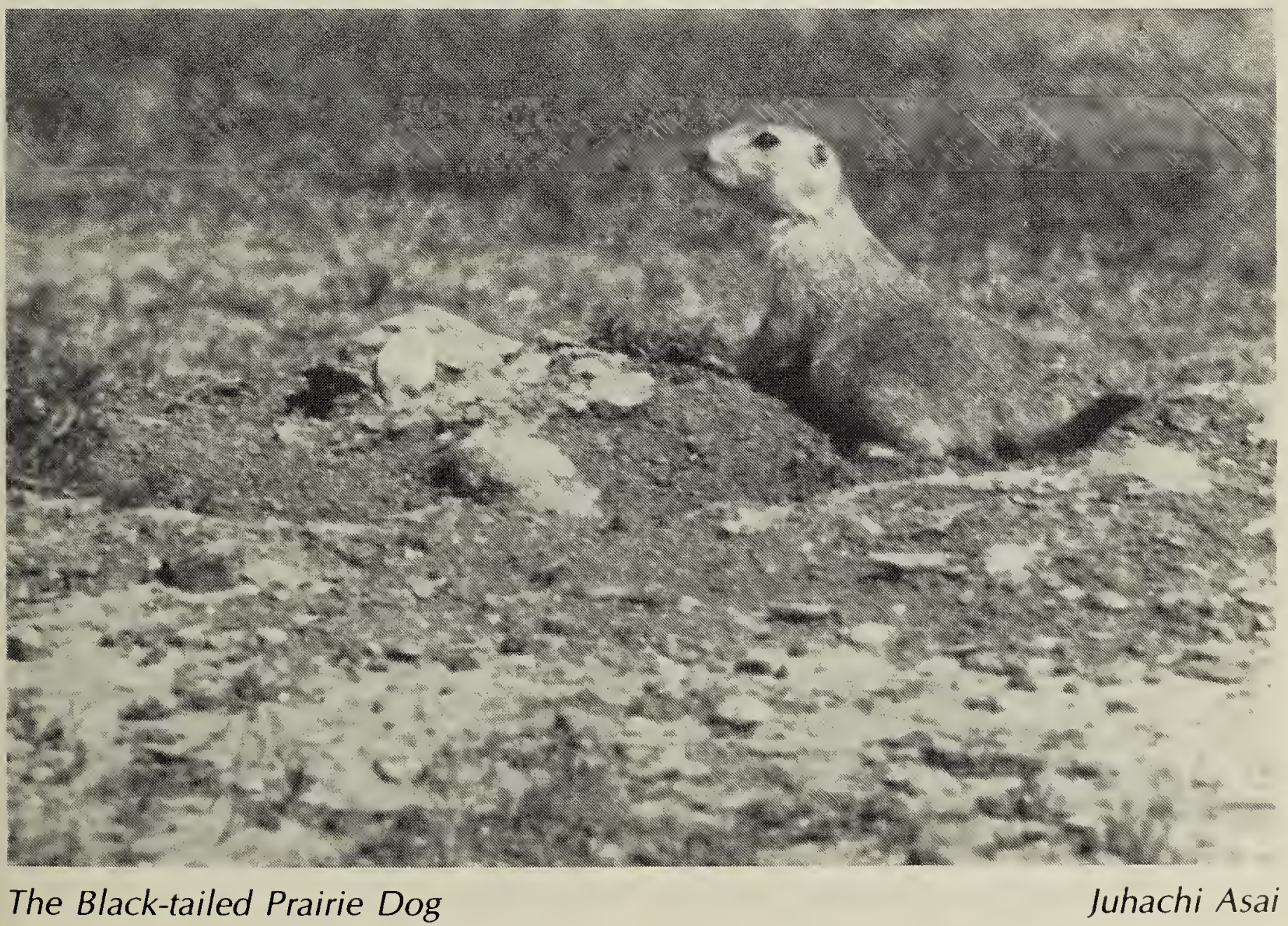


prairie dog colonies decreased to 13 , but the total occupied area increased to 763 ha (Table 1). ${ }^{5}$ Ten of these colonies, totalling 723 ha, were within the proposed Grasslands National Park boundary. Between 1970 and 1975, the total area of prairie dog occupied habitat increased by $52 \% .{ }^{5}$ Average colony size increased from 33.5 ha in 1970 to 58.6 ha in 1975 .

In 1985, 14 prairie dog colonies were located. They averaged 48.9 ha in size and totalled 684.5 ha (Figure 1). Only the colonies within the proposed park boundary were accurately mapped. The area of the two colonies located outside the boundary was estimated by visual inspection. Despite receiving protection under the Provincial Wildlife Act in 1981, there was a decrease of approximately 78 ha or $10 \%$ in total prairie dog occupied area between 1975 and 1985 . Three colonies (Colonies B, I and J) decreased significantly in size with Colony B showing the greatest decline. In 1981, a major part of this colony was cultivated, destroying the habitat for prairie dogs (F. Perrault, pers. comm.). Colonies I and J decreased in size by approximately $50 \%$ for unknown reasons. Despite legal protection for prairie dogs, illegal controls could still be affecting colony expansion. Spent shells were found in several colonies, however, they were not common and probably represented only a minor influencing factor. The poisoning of prairie dogs could explain the decrease in size of some colonies but no physical evidence of poisoning was found. Significant increases in Colony 0 and $Q$ suggest that climatic factors were not responsible for decreases in Colony I and J.

\section{Prairie Dog Density}

Prairie dog density was not determined in 1975 or 1985 . Guidelines for estimating prairie dog population size using visual counts have been developed from research in the United States. The visual count method provides a reliable and inexpensive censusing technique and is highly recommended to estimate prairie dog density in Saskatchewan. Accurate prairie dog density estimates require site

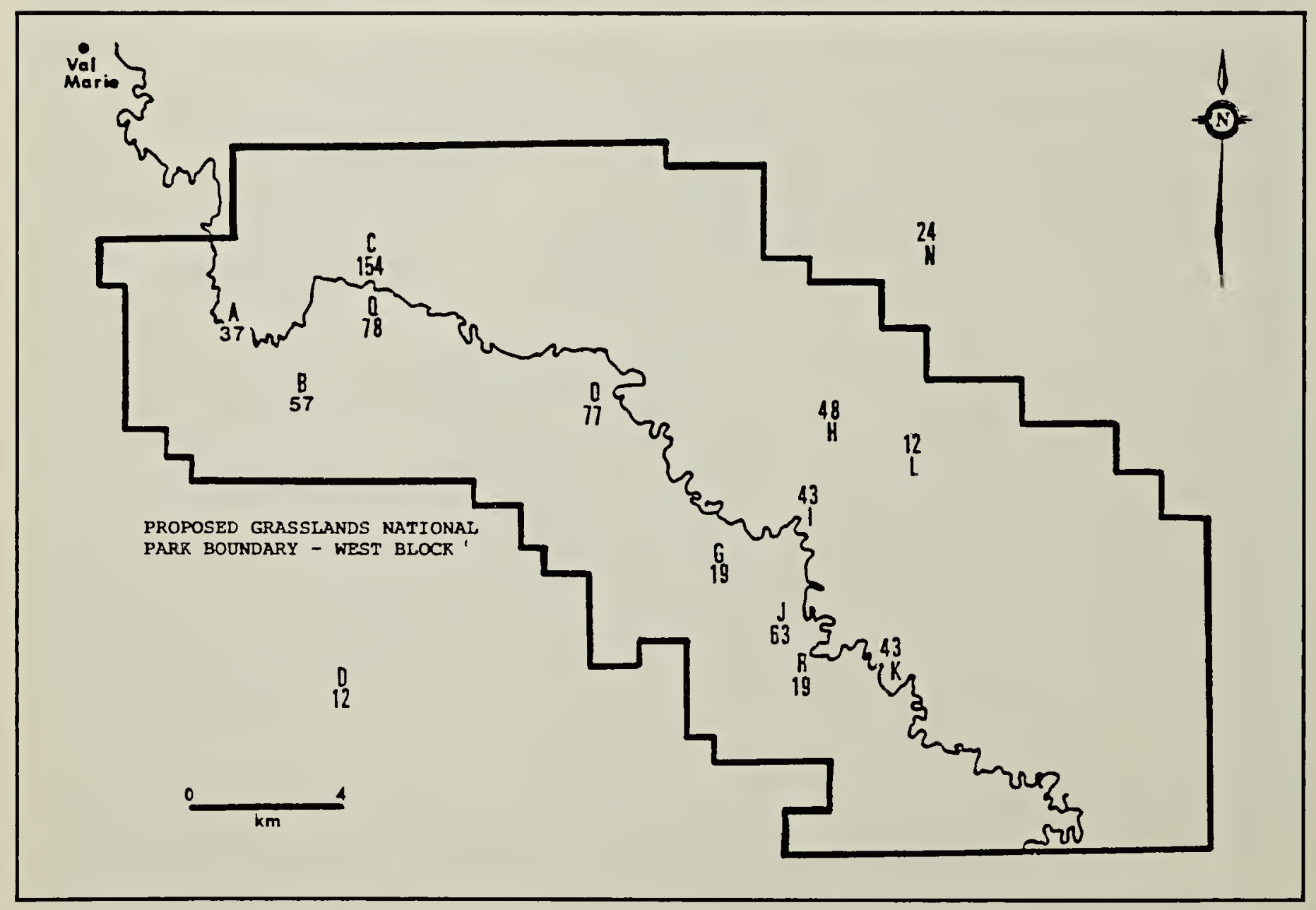

Figure 1. Location and size (ha) of prairie dog colonies in Saskatchewan in 1985. 
TABLE 1. SIZE OF SASKATCHEWAN PRAIRIE DOG COLONIES IN 1970, 1975 AND 1985.*

COLONY

A
B
$C$
D
E
F
C
$H$
1
$J$
K
L
$M$
$N$
$O$
$P$
Q
R

TOTAL

MEAN
SIZE $1970^{7}$

30.3

103

0.6

2

0.4

0.8

34.3

53.7

44.4

92.9

0.4

18.2

0.2

121.2

0.4

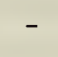

-
SIZE $1975^{5}$

31

254

164

8

$\mathrm{NL}$

$\mathrm{NL}$

17.6

40

80

120

7.2

4

$\mathrm{NL}$

24

4.4

8.8

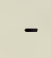

763

58.6
SIZE $1985^{4}$

37

57

154

12

$\mathrm{NL}$

$\mathrm{NL}$

19

48

43

63

43

EST 12

$\mathrm{NL}$

EST 24

77

$\mathrm{NL}$

78

19.5

684.5

48.9

* Area in hectares. NL-not located EST-area estimated

4 Laing 1986

7 Kerwin and Scheelhaase 1971 cited in Millson $1976 .^{5}$

specific analysis. Large density variations have been found between regions and between colonies within regions.

\section{Summary}

In 1975 Millson identified approximately 5800 ha of potential prairie dog habitat, most of which was within the proposed park. ${ }^{5}$ Given the availability of suitable habitat, the $52 \%$ increase in total prairie dog occupied area between 1970 and 1975 , and the fact that prairie dogs received legal protection under the Wildlife Act in 1981, an increase in total occupied area was expected in 1985. While the number of colonies did increase, there was a net decline in total occupied area. The major reason for the decline was habitat loss due to cultivation. Other potential factors influencing prairie dog expansion include: drought, overgrazing, and poisoning.
Despite the net loss of occupied area, Black-tailed Prairie Dogs are not in any immediate danger of becoming threatened or endangered. The loss is of concern, but has not yet jeopardized prairie dogs in Saskatchewan. The primary concern is that several colonies occur on privately owned land where they are vulnerable to land-use change. Cultivation of native grasslands, and poisoning programs were historically responsible for greatly reducing and segmenting prairie dog colonies. Additional habitat losses would reduce the viability of prairie dogs in Saskatchewan. Legislation to protect Saskatchewan's prairie dogs from human land-use practices is recommended. This may require compensation to land owners. Studies in the United States have shown that there is a small economic loss to ranchers as prairie dogs compete with cattle for forage. ${ }^{6}$ 
Establishment of the Grasslands $\mathrm{Na}$ tional Park should ensure the long-term survival of prairie dogs. National park legislation will protect prairie dogs and their habitat from poisoning, shooting and severe land alterations. Prairie dogs will very likely become popular with park visitors and add to their enjoyment and understanding of the complex and fascinating prairie ecosystem.

1 FAGERSTONE, K.A. and D.E. BIGGINS 1986. Comparison of capture-recapture and visual count indices of prairie dog densities in black-footed ferret habitat. Great Bas. Nat. Memoirs No. 8. Pp. 94-99.

2 KING, J.A. 1955. Social behavior, social organization, and population dynamics in a Black-tailed Prairie Dog town in the Black Hills of South Dakota. Contributions from the Laboratory of Vertebrate Biology. Univ. of
Michigan, Ann Arbor. No. 67. 121 pp.

3 KOFORD, C.B. 1958. Prairie dogs, white faces, and Blue Grama. Wildl. Monogr. No. 3. $78 \mathrm{pp}$.

4 LAING, R. 1986. The feasibility of reintroducing the black-footed ferret to the Canadian prairie. Unpublished Masters Degree Project. The University of Calgary. Calgary, Alberta. $134 \mathrm{pp}$.

5 MILLSON, R. 1976. The black-footed ferret in the proposed Grasslands National Park. Unpublished Masters Degree Project. The University of Calgary. Calgary, Alberta. 107 pp.

6 O'MEILIA, M.E., F.L. KNOPF and J.C. LEWIS 1982. Some consequences of competition between prairie dogs and beef cattle. J. Range Mgmt. 35(5):580-584.

\section{HOUSE SPARROW KILLED BY RED SQUIRREL}

ROBERT W. NERO, Wildlife Branch, 1495 St. James Street, Winnipeg, Manitoba. R3H OW9

Although the Red Squirrel's carnivorous reputation was known to me, it was still a surprise to see one capture and run off with a House Sparrow. This happened at a bird feeder in our Winnipeg yard at 1:15 p.m., 25 July 1987. It was a bright, hot day. My wife, our son Birch, and I were relaxing in the shade $9 \mathrm{~m}$ from about 20 House Sparrows feeding close together on the lawn beneath the feeder which is fastened about $1 \mathrm{~m}$ high on a large Bur Oak. I had been casually watching the sparrows, particularly one with several white wing feathers. Suddenly, a squirrel ran up the tree with a sparrow hanging upside down in its mouth, followed by a flock of scolding sparrows. When we got to the tree the squirrel was perched on a limb about $4.6 \mathrm{~m}$ up, where it killed the sparrow. Alarmed by us, the squirrel left the sparrow on a limb and ran about $3 \mathrm{~m}$ higher. It returned shortly, retrieved the sparrow and carried it back up to the higher position. Then it left the bird and raced about the tree seeking to escape to adjacent trees. It was an adult, lactating female, presumably with young in some other yard.

The sparrow, a juvenile male weighing $25 \mathrm{gm}$, had deep lacerations on the left breast and right abdomen. It appeared to have no other injuries. Inexperienced and busily seeking food, it had apparently been taken by a surprise attack by the squirrel from around the base of the tree. This feeder regularly attracts both squirrels and several species of birds. The birds feed in the tray of the feeder as well as on the ground beneath. Often, they may be seen feeding on the ground at the same time that squirrels are in the feeder. Thus, there have been many opportunities to observe squirrel-bird interactions. Red 